\title{
Influence of Apa1 (rs7975232), Taq1 (rs731236) and Bsm 1 (rs154410) polymorphisms of vitamin D receptor on preterm birth risk in the Polish population
}

\author{
Marta Baczyńska-Strzecha, Jarosław Kalinka \\ Department of Perinatology, $1^{\text {st }}$ Chair of Obstetrics and Gynecology, Medical University in Lodz, Poland
}

\begin{abstract}
Objectives: Vitamin D receptor (VDR) is expressed in the placenta and tissues related to the immune system occurrence of various variants of VDR may modify the effects of vitamin $D$ on pregnancy.

The aim of this study was to evaluate the association between the parturients' Apa1, Taq1, and Bsm1 polymorphisms of the VDR and their combinations and the risk of preterm birth in the Polish population.

Material and methods: Determination of polymorphism forVDR was assayed using the RT-PCR method. 199 Caucasian women at childbirth were qualified:100 patients who had a spontaneous preterm birth and 99 patients who had a term birth.

Results: Three separate genotypes of the Apa1, Taq1, and Bsm1 polymorphisms were detected. No significant differences in the frequency of particular genotypes in the compared groups were found. Some of the genotype combinations were significantly more frequent in the preterm group — the bb/AA/TT genotype ( $28.0 \%$ vs. $10.1 \% ; p=0.0013)$ and the $\mathrm{BB} / \mathrm{aa} / \mathrm{tt}$ genotype $(14.0 \%$ vs. $4.04 \% \mathrm{p}=0.0277)$. The $\mathrm{Bb} / \mathrm{AA} / \mathrm{Tt}$ and the $\mathrm{BB} / \mathrm{Aa} / \mathrm{tt}$ genotypes were found only in the control group ( $16.1 \%$ and $7.0 \%$ of patients, respectively). The bb/aa/TT was significantly more frequent in the control group $(2.0 \%$ vs. $11.1 \% ; p=0,0207)$. Two genotype combinations reduced the risk of preterm birth - the Bb/AA/Tt genotype by $94 \%$ $(\mathrm{OR}=0.43,95 \% \mathrm{Cl}: 0.002-0.885, \mathrm{p}=0.041)$ and the $\mathrm{BB} / \mathrm{Aa} / \mathrm{tt}$ genotype by $98 \%(\mathrm{OR}=0.029,95 \% \mathrm{Cl}: 0.001-0.838, \mathrm{p}=0.039)$.

Conclusions: Our result suggests that there may be a relationship between certain VDR genotype combinations and the risk of preterm birth. Further research is needed in order to substantiate this finding.
\end{abstract}

Key words: pregnancy, Apa1 polimorphism, Bsm1 polimorphism, Taq1 polimorphism, preterm birth

Ginekologia Polska 2016; 87, 11: 763-768

\section{INTRODUCTION}

Adequate maternal vitamin D levels during pregnancy are essential for both maternal and fetal health. Recent studies suggest that vitamin D aids in the process of implantation, maintains normal pregnancy, supports fetal growth through delivery of calcium, controls secretion of multiple placental hormones and limits the production of proinflammatory cytokines [1]. Maternal risk of pre-eclampsia, gestation diabetes and infectious diseases has been related with low levels of maternal circulating $25(\mathrm{OH}) \mathrm{D}$ in a number of observational studies [2-4]. Few reports indicating an effect of vitamin D or vitamin D receptor polymorphisms on the duration of pregnancy have been published so far
[5-7]. Spontaneous preterm birth remains a s clinical diagnosis that encompasses many diseases of multiple etiologies. There is no single cause, marker or treatment regimen likely to be $100 \%$ sensitive, specific or successful. The role of vitamin $D$ in the pathogenesis of preterm birth is explained most commonly by its participation in immunological processes $[1,8,9]$.

Vitamin D receptor (VDR) is a mediator of the pleiotropic actions of vitamin D.

The VDR has been identified both in cells and tissues related to the immune system as well as in the placenta, where it exerts a paracrine effect. The VDR is a ligand-activated transcription factor that mediates the genomic effect of $1,25 \mathrm{OHD}$ 
in various tissues. More than 900 genes may be transcribed by VDR. The gene encoding VDR is located on the chromosome $12 q$ and has several common allelic variants. Recent studies have focused on the possible role of VDR gene variation in the development of diseases such as various types of cancers, autoimmune diseases and susceptibility to infection [10].

Among the most widely studied single nucleotide polymorphisms (SNPs) are those located in the last intron, (Bsm1 and Apal1) and the last exon (Taq1) of the gene. These genetic variations may influence VDR's RNA stability and translation efficiency, and consequently affect the transcription of target genes. Taq1 polymorphism is a synonymous site, a single base change ( $T$ to $C$ ) in codon 352 at the 3 ' end of the gene. Bsm 1 and Apa1 variants are located in the last intron of the gene and result from a single base change (A to $\mathrm{G}$ and $\mathrm{G}$ to $T$, respectively) [11].

The aim of this study was to evaluate the association between the parturients' Apa1, Taq1, and Bsm1 polymorphisms of the VDR and their combinations and the risk of preterm birth in the Polish population.

\section{MATERIAL AND METHODS}

\section{Participants and study design}

The study was carried out in 2013-2015 at the Department of Perinatology, Medical University in Lodz, Poland. Patients hospitalized at the Centre were inhabitants of the central macro-region of Poland, and formed an ethnically homogenous population.

This was a case - control study. 199 Caucasian women, of Polish origin, in single pregnancy, giving birth at the Department of Perinatology were qualified into the study. Patients were divided into two groups. The study group involved 100 women giving spontaneous preterm birth (before week 37.0 of pregnancy). The control group involved 99 women having term birth (completed week 37.0 of pregnancy). Duration of pregnancy was determined based on the date of the last menstruation, and verified with an ultrasonographic examination performed between week 11.0 and 13.6 of pregnancy.

Exclusion criteria were: multiple pregnancy, abnormal results of amniocentesis or abnormal results of the double/triple test, anatomical defects of the fetus, genetic syndromes of the fetus, iatrogenic preterm delivery, pre-pregnancy diabetes, severe arterial hypertension present before the pregnancy or pregnancy-induced, immunological disorders, maternal severe endocrine diseases and generalized infection. Additionally, patients with diseases that could affect the vitamin D level, such as chronic renal failure, post-surgical conditions of the upper alimentary tract, parathyroid diseases, hepatic problems, uncontrolled thyroid diseases, unspecific inflammatory enteral diseases, were excluded.

\section{Ethics}

The study was approved by the Bioethics Committee of the Medical University in Lodz, Poland, authorization no. RNN/74/12/KE, and all participants gave their informed consent on participation in the study. A detailed, standardized medical history was obtained from all patients. The standardized questionnaire included questions regarding demographic, medical and obstetric issues.

\section{DNA extraction}

Five-milliliter whole-blood samples taken at delivery and subsequently frozen at $-20^{\circ} \mathrm{C}$ were used.

DNA was isolated from frozen blood with the use of GeneMATRIX Quick Blood DNA Purification Kit (EURx) according to manufacturer's instructions. Two hundred microliters of blood were incubated with $10 \mu \mathrm{L}$ of Proteinase K solution and $200 \mu \mathrm{L}$ of Sol QB buffer for $15 \mathrm{~min}$ at $700^{\circ} \mathrm{C}$. Subsequently, after the addition of $200 \mu \mathrm{L}$ of $96 \%$ ethanol the solution was vortexed and centrifuged for $1 \mathrm{~min}$ at $12.000 \mathrm{rpm}$. The lysate was transferred to a QB-buffer-activated mini-column and centrifuged for $2 \mathrm{~min}$ at $12.000 \mathrm{rpm}$. After the removal of transudate the mini-column was rinsed with $500 \mu \mathrm{L}$ of Wash QB1 solution and subsequently with $500 \mu \mathrm{L}$ of the Wash QB2 solution. DNA was eluted with $100 \mu \mathrm{L}$ of Elution buffer ( $10 \mathrm{mM}$ Tris-HCl, pH 8.5) at $700^{\circ} \mathrm{C}$.The concentration and quality of such an extracted DNA was assessed by spectrophotometry (Picodrop).

The vitamin D receptor (VDR) single-nucleotide polymorphisms were analyzed using commercially available pre-made Taq Man SNP Genotyping Assays (Applied Biosystems produced in USA): VDR Apa1 (rs7975232) - assay ID: C__28977635and VDR Tag1 (rs731236) — assay ID: C__ 2404008 .

\section{Genotyping of Bsm1, Apa1, and Taq1 SNPs}

The evaluation of VDR polymorphism was carried out in the Central Scientific Laboratory, Medical University of Lodz (CoreLab). The VDR single-nucleotide polymorphism G/A (rs1544410) was analyzed using Custom ${ }^{\circledast}$ SNP Genotyping Assays (Applied Biosystems produced in USA). Primer and probe sequences were: Forward Primer 5'-AGTGTGCAGGCGATTCGTA, Reverse Primer 5'- GCAAGAGCAGAGCCTGAGTAT, Probe (A allele) 5'-VIC- CCTGCACATTCCCA, Probe (G allele) 5'-FAM- CTGCGCATTCCCA.

PCR was performed using the GeneAmp PCR System 9700 (Applied Biosystems produced in USA) in $20 \mu \mathrm{L}$ reaction volume containing $10 \mathrm{ng}$ DNA, $10 \mu \mathrm{L}$ TaqMan ${ }^{\circ}$ Universal PCR Master Mix and 0,5 $\mu \mathrm{L}(40 \times)$ appropriate TagMan ${ }^{\circ}$ SNP Genotyping Assay. The PCR thermal cycling was as follows: initial denaturing at $95^{\circ} \mathrm{C}$ for $10 \mathrm{~min} ; 40$ cycles of $92^{\circ} \mathrm{C}$ for $15 \mathrm{sec}$ and $60^{\circ} \mathrm{C}$ for $1 \mathrm{~min}$. Each 96 -well plate contained tested samples and 3 reaction mixtures without DNA template (no-template control). End-point fluorescent intensities of 
each probe were monitored using 7900HT Fast Real-Time PCR System (Applied Biosystems). The genotypes were determined automatically and verified visually using Sequence Detection System 2.3 Software.

\section{The statistical analysis}

The calculations were performed using STATISTICA PL 10.0 software. Quantitative variables were described by the mean, standard deviation (SD) and range (minimum-maximum). For categorical variables percentages (\%) are presented. Normality was tested using the Shapiro-Wilk's test for normality. Differences between two independent samples for continuous data were analyzed using U Mann-Whitney's test (if the distributions of variables were different from normal) or Student's t test (for variables normally distributed). For categorical variables statistical analysis was based on Pearson chi-squared test or chi-squared test with Yates' adjustment.

The frequency of alleles was tested against the Hardy-Weinberg equilibrium with the use of chi-squared test.

Variables significant in univariate comparisons (at $p<0.10$ ) were included into multivariate logistic regression model to identify the set of the independent risk factors of preterm delivery. The odds ratio (OR) with $95 \%$ confidence interval was presented for each potential risk factor. The results were considered statistically significant at $p \leq 0.05$.

\section{RESULTS \\ Participants}

Presence of the Apa1, Tag1, Bsm1 polymorphisms was finally studied in 199 women at child birth. The control group consisted of 99 patients at full-term ( $>37.0$ week of gestation) and the experimental group of 100 patients with preterm birth (22.0-36.6 week of gestation).

Socioeconomic data and medical history were analyzed in both groups. The mean duration of pregnancy was $33.5 \pm 3.4$ weeks in the case group and $39.4 \pm 0.9(p=0.114)$ weeks in the control group, respectively. Mean age, mean BMI, vocational activity, and living conditions did not differ in both groups $(p>0.05)$. The preterm birth group differed from the control group in the number of pregnancies $(p=0.007)$ and the number of births $(p=0.028)$. Uterine cervical insufficiency was found more often in the preterm birth group $(p<0.001)$. Similarly, premature rupture of membranes was also more frequent in this group ( $p<0.001)$. Characteristics of both groups are presented in Table 1.

\section{Frequencies of genotypes of 3 SNPs}

Three separate genotypes of the Apa1, Taq1, and Bsm1 polymorphisms were detected in the studied population. The observed genotype frequencies of Apa1, Taq1, and Bsm 1 in both analyzed groups were in agreement with Hardy-Weinberg equilibrium $\left(x^{2}=0.98, p=0.322 ; x^{2}=0.86\right.$, $p=0.354$ and $X^{2}=0.86, p=0.354$ for the preterm birth group; $x^{2}=0.81, p=0.368 ; x^{2}=0.70, p=0.403$ and $x^{2}=0.26$, $p=0.610$ for the term birth group, respectively).

The most common genotypes in the overall population for the Bsm1, Apa1 and Taq1 SNPs were Bb (46.2\%), Aa (45.2\%) and $\mathrm{Tt}$ (45.2\%), respectively. No differences in the frequencies of the individual genotypes were found between the studied groups ( $p>0.05$ ). In both groups, the wild Aa genotype for Apa 1 was the most common (PB 45.0\%, TB 45.4\%), whereas the aa genotype was the least common (PB 26.0\%, TB 26.2\%). In the preterm birth group, the bb allele for Bsm 1 (45.0\%) and the TT allele for the Taq1 polymorphism (45.0\%) were the most common, respectively. There were no statistically significant differences between the groups. The frequencies of genotypes in the studied groups are presented in Table 2.

Of the 27 possible variants of Bsm/Apa/Taq genes in the population, $5 \%$ were confirmed in the studied population.

The most frequent genotype in the studied population was the $\mathrm{Bb} / \mathrm{Aa} / \mathrm{Tt}$ genotype $(27.1 \%)$ and was found in both groups. Some of the genotype combinations presented in Table 3 were significantly more frequent in the preterm group as compared to the control group. These were the bb/AA/TT genotype (28.0\% vs. $10.1 \% ; \mathrm{p}=0.0013$ ) and the $B B / a a / t t$ genotype (14.0\% vs. $4.04 \% ; p=0.0277$ ). The $\mathrm{Bb} / \mathrm{AA} / \mathrm{Tt}$ (16.1\%) and the $\mathrm{BB} / \mathrm{Aa} / \mathrm{tt}$ (7.0\%) genotypes were found only in the control group. The bb/aa/TT was significantly more frequent in the control group (2.0\% vs. $11.1 \%$; $p=0.0207)$.

\section{Effect of genotype on the risk of preterm birth}

Logistic regression models were used in order to determine if the above-mentioned haplotype combinations were associated with the risk of preterm birth. Variables that were significant at $p<0.10$ in univariate analyzes were included in the multivariable model. Apart from the polymorphisms, they included maternal body weight, number of pregnancies, number of deliveries, history of miscarriage, tobacco use, infection during pregnancy, premature rupture of membranes and cervical incompetence. The analysis revealed two significant independent factors increasing the risk of preterm birth. These were premature rupture of membranes and cervical incompetence. Moreover, two genotype combinations reduced the risk of preterm birth - the $\mathrm{Bb} / \mathrm{AA} / \mathrm{Tt}$ genotype by $83 \%(\mathrm{OR}=0.173 ; 95 \% \mathrm{Cl}$ : $0.024-1.264 ; \mathrm{p}=0.084$ ) and the $\mathrm{BB} / \mathrm{Aa} / \mathrm{tt}$ genotype by $98 \%$ $(\mathrm{OR}=0.029 ; 95 \% \mathrm{Cl}: 0.001-0.838 ; \mathrm{p}=0.039)$. The results are presented in Table 4.

\section{DISCUSSION}

Our study showed that individual maternal polymorphisms of the VDR gene, namely the Taq1, Bsm1 and 
Table 1. Patient characteristics

\begin{tabular}{|c|c|c|c|}
\hline \multirow[t]{2}{*}{ Variables } & $\begin{array}{l}\text { Preterm birth } \\
\qquad N=100\end{array}$ & $\begin{array}{l}\text { Term birth } \\
\mathrm{N}=99\end{array}$ & $\mathbf{p}$ \\
\hline & \multicolumn{3}{|c|}{ Mean \pm SD $(\min -\max )$} \\
\hline Age (years) & $31.0 \pm 5.0(19-42)$ & $29.9 \pm 4.5(19-40)$ & 0.114 \\
\hline BMI $\left[\mathrm{kg} / \mathrm{m}^{2}\right]$ & $26.6 \pm 4.6(18.7-39.3)$ & $27.1 \pm 3.3(18.6-38.8)$ & 0.198 \\
\hline Body weight [kg] & $71.66(46-112)$ & $74.58(55-108)$ & 0.019 \\
\hline Number of pregnancies & $2 \pm 1.2(1-7)$ & $1.6 \pm 0.8(1-4)$ & 0.007 \\
\hline \multirow[t]{2}{*}{ Number of births } & $1.7 \pm 1.0(1-7)$ & $1.4 \pm 0.6(1-4)$ & 0.028 \\
\hline & \multicolumn{3}{|c|}{ Percentages (\%) } \\
\hline Uterine cervix insufficiency & $25 \%(n=25)$ & $4.04 \%(n=4)$ & $<0.001$ \\
\hline Premature rupture of membranes & $66 \%(n=66)$ & $24.24 \%(n=24)$ & $<0.001$ \\
\hline Miscarriages & $19.57 \%(n=18)$ & $8.91 \%(n=9)$ & 0.030 \\
\hline Nicotinism & $19.19 \%(n=19)$ & $10.10 \%(n=10)$ & 0.071 \\
\hline Infections & $25.51 \%(n=25)$ & $15.15 \%(n=15)$ & 0.071 \\
\hline
\end{tabular}

Table 2. Genotype frequencies for single-nucleotide polymorphisms (SNPs) Apa1, Bsm1, Taq1 in the vitamin D receptor (VDR) in all patients with preterm birth and control subjects

\begin{tabular}{|l|c|c|c|}
\hline SNP & $\begin{array}{c}\text { Total population } \\
\mathbf{N = 1 9 9 ( \% )}\end{array}$ & $\begin{array}{c}\text { Preterm birth } \\
\mathbf{N = 1 0 0}(\%)\end{array}$ & $\begin{array}{c}\text { Term birth } \\
\mathbf{N}=99(\%)\end{array}$ \\
\hline Apal (rs7975232) & & & $28(28.28 \%)$ \\
\hline AA & $57(28.64 \%)$ & $29(29.00 \%)$ & $45(45.45 \%)$ \\
\hline Aa & $90(45.23 \%)$ & $45(45.00 \%)$ & $26(26.26 \%)$ \\
\hline aa & $52(26.13 \%)$ & $26(26.00 \%)$ & \\
\hline P-value & & 0.9938 & $13(13.13 \%)$ \\
\hline Bsml (rs154410) & $27(13.57 \%)$ & & $51(51.51 \%)$ \\
\hline BB & $92(46.23 \%)$ & $14(14.00 \%)$ & $35(35.35 \%)$ \\
\hline Bb & $80(40.20 \%)$ & $41(41.00 \%)$ & \\
\hline bb & & $45(45.00 \%)$ & $37(37.37 \%)$ \\
\hline P-value & & 0.3059 & $49(49.49 \%)$ \\
\hline Tagl (rs731236) & $82(41.21 \%)$ & $45(45.00 \%)$ & $13(13.13 \%)$ \\
\hline TT & $90(45.23 \%)$ & $41(41.00 \%)$ & $14(14.00 \%)$ \\
\hline Tt & $27(13.57 \%)$ & 0.4668 & \\
\hline tt & & & \\
\hline P-value & & & \\
\hline
\end{tabular}

Table 3. Multiple haplotype combinations frequencies for Bsm-Apa-Taq in all patients with preterm birth and control subjects

\begin{tabular}{|c|c|c|c|c|}
\hline Bsm-Apa-Taq & $\begin{array}{l}\text { Total population } \\
\qquad N=199(\%)\end{array}$ & $\begin{array}{l}\text { Preterm birth } \\
\mathrm{N}=100(\%)\end{array}$ & $\begin{array}{l}\text { Term birth } \\
N=99(\%)\end{array}$ & P-value \\
\hline bb/AA/TT & 38 (19.10\%) & $28(28.00 \%)$ & $10(10.10 \%)$ & 0.0013 \\
\hline $\mathrm{Bb} / \mathrm{AA} / \mathrm{Tt}$ & 16 (8.04\%) & $0(0)$ & $16(16.16 \%)$ & 0.0001 \\
\hline bb/aa/TT & $13(6.53 \%)$ & $2(2.00 \%)$ & $11(11.11 \%)$ & 0.0207 \\
\hline BB/aa/tt & $18(9.05 \%)$ & 14 (14.00\%) & 4 (4.04\%) & 0.0277 \\
\hline $\mathrm{Bb} / \mathrm{aa} / \mathrm{Tt}$ & 19 (9.55\%) & $9(9.00 \%)$ & $10(10.10 \%)$ & 0.7916 \\
\hline $\mathrm{bb} / \mathrm{Aa} / \mathrm{TT}$ & 28 (14.07\%) & $14(14.00 \%)$ & $14(14.14 \%)$ & 0.9771 \\
\hline $\mathrm{BB} / \mathrm{Aa} / \mathrm{tt}$ & 7 (3.52\%) & $0(0)$ & 7 (7.07\%) & 0.0202 \\
\hline $\mathrm{Bb} / \mathrm{Aa} / \mathrm{Tt}$ & $54(27.14 \%)$ & 31 (31.00\%) & $23(23.23 \%)$ & 0.2179 \\
\hline
\end{tabular}




\begin{tabular}{l|c|c|c|c|}
\hline $\begin{array}{l}\text { Table 4. Logistic regression model }(\mathrm{X}=67.12, \mathrm{df}=10, \mathrm{p}<0.001 \\
\text { - statistically significant model) }\end{array}$ \\
\hline Variables & OR & $95 \%$ Cl for OR & P-value \\
\hline Body weight & 0.986 & 0.954 & 1.019 & 0.394 \\
\hline Number of pregnancies & 1.467 & 0.240 & 8.984 & 0.679 \\
\hline Number of births & 0.953 & 0.136 & 6.685 & 0.961 \\
\hline Miscarriages & 0.646 & 0.050 & 8.409 & 0.738 \\
\hline Tobacco use & 1.263 & 0.369 & 4.326 & 0.710 \\
\hline Infections & 1.565 & 0.598 & 4.096 & 0.361 \\
\hline Premature rupture of & 6.953 & 2.946 & 16.414 & 0.000 \\
\hline membranes & 6.921 & 1.715 & 27.934 & 0.007 \\
\hline Cervical incompetence & 2.243 & 0.796 & 6.325 & 0.127 \\
\hline bb/AA/TT & 0.043 & 0.002 & 0.885 & 0.041 \\
\hline Bb/AA/Tt & 0.173 & 0.024 & 1.264 & 0.084 \\
\hline bb/aa/TT & 2.214 & 0.466 & 10.524 & 0.318 \\
\hline BB/aa/tt & 0.029 & 0.001 & 0.838 & 0.039 \\
\hline BB/Aa/tt & & &
\end{tabular}

Apa1 polymorphisms, do not influence the risk of preterm birth, but some genotype combinations, i.e. the Bb/AA/Tt reduces the risk by $94 \%$ and $\mathrm{BB} / \mathrm{Aa} / \mathrm{tt}$ genotypes, reduce this risk by $98 \%$. However, these findings should be confirmed in larger populations. The frequencies of the individual genotypes of Apa1, Taq1 and Bsm 1 obtained in our study were similar to those from previous studies carried out in Caucasians.

There have been few studies investigating the association between preterm birth and VDR polymorphisms. Manzon et al. studied the influence of the Fok1, Apa1, Taq1 and Bsm1 polymorphisms on the risk of idiopathic spontaneous preterm birth in an Israeli population. In that study, maternal Fok 1 and Taq 1 VDR allele frequencies were significantly different in the preterm birth group as compared to the control group. However, only the maternal Fok 1 variant was associated with an increased risk of preterm birth $(\mathrm{OR}=3.317)$. The ORs for the other variants such as Taq1, Bsm 1 or Apa1 were insignificant. In contrast to our study, multiple haplotype combinations were not analyzed in the study of Manzon et al. because of a limited number of samples - only 33 samples in the preterm birth group [5].

Fang et al. studied the influence of single-nucleotide polymorphisms in the MTHRF, VDR, MMP- 9 and II- $\beta$ genes and the risk of premature rupture of membranes. They reported that, compared to the patients in the stratum of 40 or more weeks of gestation, those in the stratum of 37 or fewer weeks of gestation had an increased risk of premature rupture of membranes when carrying the TT genotype of Taq1 (OR $=6.08 ; 95 \% \mathrm{Cl}$ : 1.39-26.60). They confirmed the interaction between genetic factors including VDR polymorphisms and the occurrence of premature rupture of membranes which is in itself a preterm birth risk factor. In our study, the frequency of premature rupture of membranes was the same in both groups and did not differ between individual VDR polymorphisms or their combinations. However, the study of Fang et al. was conducted in a Chinese population which is genetically different from our population. The incidence of VDR polymorphisms and their relationship to certain features is different in Asians than in Caucasians. Moreover, the above-mentioned study was underpowered with only 18 pregnant women $<37$ weeks of gestation with premature rupture of membranes [12].

The role of vitamin $D$ in the pathogenesis of preterm birth is explained most commonly by its participation in immunological processes. Vitamin D mediates many immuno-modulatory effects through the VDR. The VDR is found in many immune cells such as macrophages, dendritic cells, $T$ and $B$ lymphocytes, and it plays a vital role in the innate immune response [13]. Vitamin $D$ is involved in cell-mediated immunity where it is thought to reduce the production of inflammatory cytokines such as IL-1, IL-6, and TNF-a that are involved in the spontaneous preterm birth $[14,15]$. Polymorphisms in the VDR gene have been associated with autoimmune and infectious diseases such as tuberculosis, Crohn's disease, asthma or diabetes [16-19]. Maintenance of a normal pregnancy requires efficient coordination of antimicrobial and anti-inflammatory responses within the feto-placental unit. Vitamin D plays a significant role in modulating both of these processes, thereby helping to maintain a pregnancy [20]. The Taq1, Bsm1, and Apa1 polymorphisms of the VDR gene may affect mRNA stability leading to a change in protein levels and an imbalance between the Th1 and Th2 related cytokines, which is crucial in determining the clinical outcome of preterm birth. However, the role of different VDR alleles remains unclear $[21,22]$. Several studies have examined the association between the common Bsm1/Apa1/Taq1 haplotypes and VDR function. Some studies associate the BBAAtt allelotypes of the VDR with an increased risk of osteoporosis in postmenopausal women [23]. Morrison et al. showed that COS-7 and rat osteosarcoma cells transfected with reporter gene constructs containing the baT haplotype had a significantly lower luciferase activity than those with the Bat haplotype [24]. In contrast, Beaumont et al. demonstrated a significantly greater luciferase activity with reporter gene constructs containing the baT haplotype in transfected human osteoblast and osteosarcoma cell lines [25]. Possible explanation for these inconsistent findings may be that the effect of VDR allelic variants on VDR function is tissue specific. The determination of the relationship between the individual haplotypes of the VDR gene in the feto-placental unit requires further research involving a larger number of participants. 
One of the main merits of our study is that it contributes to the understanding of the association between VDR polymorphisms and spontaneous preterm birth in Caucasians. However, there are also limitations to our study such as a relatively low number of participants. Furthermore, because of the complexity of the gene-gene and gene-environment interactions, larger, multi-center studies are needed in order to confirm the relationship between the genotype and the risk of preterm birth. Moreover, a greater number of VDR polymorphisms and their combinations should be analyzed. Genetic, ethnic and racial differences as well as the latitude of residence may account for the discrepancies in health outcomes. Therefore, other populations should be investigated as well.

\section{CONCLUSIONS}

In summary, our study suggests that there is a relationship between certain VDR genotype combinations and the risk of preterm birth. Further research is needed in order to substantiate this finding. A more detailed understanding of the genetic and environmental risks of the preterm birth will allow for a more personalized approach to preterm birth management and its prevention. In particular, it will allow for an early identification of patients at risk of preterm birth.

\section{Conflict of interest}

The authors report no conflict of interest.

\section{Acknowledgements}

The study was supported by scientific grant from Medical University of Lodz No. 502-03/1-004-03/502-14-158.

\section{REFERENCES}

1. Liu NQ, Hewison M.Vitamin D, the placenta and pregnancy. Arch Biochem Biophys. 2012, 523, 37-47.

2. Robinson $\mathrm{CJ}$, Alanis $\mathrm{MC}$, Wagner $\mathrm{CL}$, [et al.]. Plasma 25 -hydroxyvitamin D levels in early-onset severe preeclampsia. Am J Obstet Gynecol. 2010, 203, 366.

3. Zhang MX, Pan GT, Guo JF, [et al.]. Vitamin D Deficiency Increases the Risk of Gestational Diabetes Mellitus: A Meta-Analysis of Observational Studies. Nutrients. 2015, 7, 8366-8375.

4. Hensel KJ, Randis TM, Gelber SE, [et al.]. Pregnancy-specific association of vitamin D deficiency and bacterial vaginosis. Am J Obstet Gynecol. $2011,204,41$
5. Manzon L, Altarescu G, Tevet A, [et al.]. Vitamin D receptor polymorphism Fokl is associated with spontaneous idiopathic preterm birth in an Israeli population. Eur J Obstet Gynecol Reprod Biol. 2014, 177, 84-88.

6. Bodnar LM, Platt RW, Simhan HN. Early-pregnancy vitamin D deficiency and risk of preterm birth subtypes. Obstet Gynecol. 2015, 125, 439-447.

7. Wagner CL, Baggerly C, McDonnell SL, [et al.]. Post-hoc comparison of vitamin $\mathrm{D}$ status at three timepoints during pregnancy demonstrates lower risk of preterm birth with higher vitamin D closer to delivery. J Steroid Biochem Mol Biol. 2015, 148, 256-260.

8. Evans KN, Bulmer JN, [et al.]. Vitamin D and placental-decidual function. J Soc Gynecol Investig. 2004, 11, 263-271.

9. Evans KN, Nguyen L, Chan J,[ et al.]. Effects of 25-hydroxyvitamin D3 and 1,25-dihydroxyvitamin D3 on cytokine production by human decidual cells. Biol Reprod. 2006, 75, 816-822.

10. Zmuda JM, Cauley JA, Ferrell RE. Molecular epidemiology of vitamin D receptor gene variants. Epidemiol Rev. 2000, 22, 203-217.

11. Uitterlinden AG, Fang Y, Van Meurs JB, [et al.]. Genetics and biology of vitamin D receptor polymorphisms. Gene. 2004, 338, 143-156.

12. Fang $X$, Li H, Diao Y, [et al.]. Polymorphisms in the MTHRF, VDR, MMP-9 and IL- $\beta$ genes and the risk of premature rupture of membranes. Gynecol Obstet Invest. 2010, 70, 206-214.

13. Evans KN, Bulmer JN, Kilby MD, [et al.]. Vitamin D and placental-decidual function. J Soc Gynecol Investig. 2004, 11, 263-271.

14. Díaz L, Noyola-Martínez N, Barrera D, [et al.]. Calcitriol inhibits TNF-alpha-induced inflammatory cytokines in human trophoblasts. J Reprod Immunol. 2009, 81, 17-24

15. Helming L, Böse J, Ehrchen J, [et al.]. 1alpha,25-Dihydroxyvitamin D3 is a potent suppressor of interferon gamma-mediated macrophage activation. Blood. 2005, 106, 4351-4358.

16. Lee $\mathrm{YH}$, Song GG. Vitamin D receptor gene Fokl, Taql, Bsml, and Apal polymorphisms and susceptibility to pulmonary tuberculosis: a meta-analysis. Genet Mol Res. 2015, 14, 9118-9129

17. Wang L, Wang ZT, Hu JJ, [et al.] Polymorphisms of the vitamin D receptor gene and the risk of inflammatory bowel disease: a meta-analysis. Genet Mol Res. 2014, 13, 2598-610.

18. Jia J, Ding H, Yang K, [et al.]. Vitamin D Receptor Genetic Polymorphism Is Significantly Associated with Risk of Type 2 Diabetes Mellitus in Chinese Han Population. Arch Med Res. 2015, 46, 572-579.

19. Tizaoui K, Berraies A, Hamdi B, [et al.]. Association of vitamin D receptor gene polymorphisms with asthma risk: systematic review and updated meta-analysis of case-control studies. Lung. 2014, 192, 955-965.

20. Liu NQ, Kaplan AT, Lagishetty V, [et al.]. Vitamin D and the regulation of placental inflammation. J Immunol. 2011, 186, 5968-5974.

21. Le Hir H, Nott A, Moore MJ. How introns influence and enhance eukaryotic gene expression. Trends Biochem Sci. 2003, 28, 215-220.

22. Durrin LK, Haile RW, Ingles SA, [et al.]. Vitamin D receptor 3 '-untranslated region polymorphisms: lack of effect on mRNA stability. Biochim Biophys Acta. 1999, 1453, 311-320.

23. Gennari L, Becherini L, Masi L, [et al.]. Vitamin D and estrogen receptor allelic variants in Italian postmenopausal women: evidence of multiple gene contribution to bone mineral density. J Clin Endocrinol Metab. 1998, 83, 939-944.

24. Morrison NA, Qi JC, Tokita A, [et al.]. Prediction of bone density from vitamin D receptor alleles. Nature. 1994, 367, 284-287.

25. Beaumont $M$, Bennett $A J$. Allelic differences in the 3 ' untranslated region of the vitamin D receptor gene affect mRNA levels in bone cells. (Abstract). Osteoporos Int. 1998, 8, 37. 